\title{
Hypoxia-induced miR-181b enhances angiogenesis of retinoblastoma cells by targeting PDCD10 and GATA6
}

\author{
XIAOFANG XU, SHENGFANG GE, RENBING JIA，YIXIONG ZHOU，XIN SONG, \\ HE ZHANG and XIANQUN FAN \\ Department of Ophthalmology, Shanghai Ninth People's Hospital, \\ Shanghai Jiao Tong University School of Medicine, Shanghai 200011, P.R. China
}

Received December 22, 2014; Accepted February 19, 2015

DOI: $10.3892 /$ or.2015.3900

\begin{abstract}
Previous findings showed that miR-181b is upregulated under hypoxic conditions in retinoblastoma cells. Since hypoxia is a common feature of retinoblastoma that affects tumor progression as well as tumor therapy, in the present study, we investigated the regulatory mechanism of miR-181b under hypoxic conditions, and examined the role of miR-181b in retinoblastoma responses to hypoxia (chemoresistance and angiogenesis) and possible downstream genes. The level of hypoxia-inducible factor- $1 \alpha(\mathrm{HIF}-1 \alpha)$ and miR-181b was detected to examine the link between them. Tube formation and cell cytotoxicity assays were used to clarify the effects of miR-181b on hypoxic responses of retinoblastoma cells. Bioinformatics analysis was performed to predict potential targets of miR-181b and western blotting was used to verify these targets. The results showed a significantly increased expression of HIF-1 $\alpha$ in hypoxia-treated retinoblastoma cells. Downregulation of HIF-1 $\alpha$ using a small-interfering RNA (siRNA) knockdown technology did not decrease the expression of miR-181b. Through gain- and loss-of-function studies, miR-181b was demonstrated to significantly stimulate the ability of capillary tube formation of endothelial cells. Programmed cell death-10 (PDCD10) and GATA binding protein 6 (GATA6) were identified as the target genes of miR-181b. To the best of our knowledge, results of the present study provide the first evidence that miR-181b was upregulated by hypoxia in retinoblastoma in an HIF-1 $\alpha$-independent manner. miR-181b increased tumor angiogenesis of retinoblastoma cells. Additionally, miR-181b exerts its angiogenic function, at least in part, by inhibiting PDCD10 and GATA6. Thus, it is a new potentially useful therapeutic target for retinoblastoma.
\end{abstract}

Correspondence to: Professor Xianqun Fan or Dr Renbing Jia, Department of Ophthalmology, Shanghai Ninth People's Hospital, Shanghai Jiao Tong University School of Medicine, 639 Zhi Zao Ju Road, Shanghai 200011, P.R. China

E-mail: fanxq@sh163.net

E-mail: jrb19760517@hotmail.com

Key words: miR-181b, angiogenesis, retinoblastoma, hypoxia

\section{Introduction}

Retinoblastoma is the most common and malignant intraocular tumor in children (1). Chemotherapy combined with local therapy has become the first-line treatment for early retinoblastoma, and over $95 \%$ of patients with retinoblastoma survive their malignancy in developed countries (2). However, once extraocular dissemination occurred, the rate of ocular salvage and patient survival were low. The leading cause of treatment failure and cancer-associated mortalities in retinoblastoma are chemoresistance and metastasis to distant organs. This is particularly prominent in developing countries due to the ignorance of the parents, and delay in referral which is associated with delayed diagnosis and treatment $(3,4)$.

Hypoxia is a common feature of solid tumor including retinoblastoma and responses of tumor cells to hypoxia are important for tumor progression as well as tumor therapy. Previous studies demonstrated that hypoxic responses of tumor cells were involved in various biological processes including cellular proliferation, apoptosis, chemotherapy resistance, angiogenesis and migration (5-7). Thus, the presence of a hypoxic region in retinoblastoma may be a common pathway mediating chemoresistance and metastasis, rendering hypoxia a new therapeutic target. Hypoxic responses are an outcome of the interplay between the tumor cells and microenvironment. However, the exact mechanism was a complicated process involving the coordination of different factors that have not been adequately understood yet.

MicroRNAs (miRNAs) are a family of small non-coding RNA oligonucleotides that regulate gene expression by binding to sites in the 3'-untranslated region (3'-UTR) of the corresponding mRNA. Dysregulation of miRNAs is a key process involved in each stage of many cancer types from initiation to metastasis. Studies have shown there is a functional link between hypoxia and miRNA dysregulation (also termed hypoxia-regulated miRNAs, HRMs) which plays an important role in cell survival in low oxygen environment in cancer (8-10).

We identified miR-181b as an HRM in retinoblastoma cells that stimulated proliferation of retinoblastoma cells in our previous study (11). However, the function of miR-181b in retinoblastoma has yet to be elucidated. In the present study, we aim to investigate the regulatory mechanism of miR-181b 
under hypoxic conditions and evaluate the possible roles of miR-181b in hypoxic responses of retinoblastoma cells.

\section{Materials and methods}

Cell and culture. HXO-RB44 cells (human retinoblastoma cells) were provided by Professor Heping Xu (Zhongnan University, China) and human umbilical vein endothelial cells (HUVECs) were purchased from the Type Culture Collection of the Chinese Academy of Sciences (Shanghai, China). HXO-RB44 cells were cultured in RPMI-1640 medium containing 10\% fetal bovine serum (FBS) (both from Gibco-BRL, Grand Island, NY, USA) in an incubator $\left(37^{\circ} \mathrm{C}, 5 \% \mathrm{CO}_{2}\right)$. HUVECs were grown in M-199 medium (Gibco-BRL) with 20\% FBS, $100 \mathrm{U} / \mathrm{ml}$ penicillin (Biological Industries, Bet Haemek, Israel) and $1 \mathrm{U} / \mathrm{ml}$ fibroblast growth factor 2 (FGF2; Upstate Biotechnology, Lake Placid, NY, USA) in a humidified incubator $\left(37^{\circ} \mathrm{C}, 5 \% \mathrm{CO}_{2}\right)$. To induce hypoxic conditions, the cells were maintained in an InVivo200 hypoxia workstation (Biotrace International, Ruskinn Life Sciences, UK) with a steady flow of gas mixture $\left(1 \% \mathrm{O}_{2}, 5 \%\right.$ $\mathrm{CO}_{2}$ and $94 \% \mathrm{~N}_{2}$ ).

Small-interfering RNA (siRNA)-mediated hypoxia-inducible factor-1 $\alpha(H I F-1 \alpha)$ silencing. siRNAs targeting HIF-1 $\alpha$ and a scrambled sequence (GenePharma, Shanghai, China) were transfected into HOX-RB44 cells according to the manufacturer's instructions. Briefly, the cells were plated into 24-well plates $\left(5 \times 10^{5}\right.$ cells/well) with FBS-free medium overnight. The cells were tranfected with siHIF-1 $\alpha$ and scrambled sequence using Lipofectamine 2000 reagent (Invitrogen, Carlsbad, CA USA). After $6 \mathrm{~h}$, the cells were re-fed with fresh medium containing 10\% FBS and experiments were performed $48 \mathrm{~h}$ later. Sequences for the siRNA of HIF-1 $\alpha$ used in this study were: siHIF-1 $\alpha-816$ forward, GCUCAAUUUAUGAAU AUUATT and reverse, UAAUAUUCAUAAAUUGAGCGG; siHIF- $1 \alpha-1171$ forward, GAAGGAACCUGAUGCUUU ATT and reverse, UAAAGCAUCAGGUUCCUUCTT; siHIF- $1 \alpha-1504$ forward, CGAUGGAAGCACUAGACAATT and reverse, UUGUCUAGUGCUUCCAUCGGA.

Detection of the expression of HIF-1 $\alpha$. Total RNA was isolated from HXO-RB44 cells using TRIzol reagent (Invitrogen) according to the manufacturer's instructions. RNA integrity was assessed using NanoDrop (Thermo Fisher Scientific Inc., Wilmington, DE, USA). RNA ( $2 \mu \mathrm{g})$ was reverse transcribed into single-strand DNA using the First Strand Synthesis kit (Invitrogen). The resulting cDNA was used to perform quantitative PCR with Rotor-Gene 3000 Real-Time PCR System (Corbett Robotics, Australia) using SYBR-Green reporter dye (Invitrogen) and $\beta$-actin was used for normalization. The PCR amplification protocol was $95^{\circ} \mathrm{C}$ for 1 min followed by 40 cycles of $95^{\circ} \mathrm{C}$ for $15 \mathrm{sec}, 62^{\circ} \mathrm{C}$ for $15 \mathrm{sec}, 72^{\circ} \mathrm{C}$ for $30 \mathrm{sec}$, then followed by $95^{\circ} \mathrm{C}$ for $15 \mathrm{sec}, 60^{\circ} \mathrm{C}$ for $1 \mathrm{~min}, 95^{\circ} \mathrm{C}$ for $30 \mathrm{sec}$ and a $30-\mathrm{sec}$ final extension at $37^{\circ} \mathrm{C}$. Specific primers (Sangon Biotech Inc., Shanghai, China) used for HIF-1 $\alpha$ were: forward, CGTTCCTTCGATCAGTTGTC and reverse, TCAGTGGTGGCAGTGGTAGT. The primer sequences for $\beta$-actin were: forward, CTCCATCCTGGCCTCGCTGT and reverse, GCTGTCACCTTCACCGTTCC. The relative expression was analyzed using the $2^{-\Delta \Delta \mathrm{Ct}}$ method and all the experiments were performed in triplicate.

Transfection of miRNAs. HXO-RB44 cells in the exponential growth phase were seeded in 24 -well plates $\left(4 \times 10^{4}\right.$ cells/well). miR-181b precursor and inhibitor and the negative control (Ambion, Foster City, CA, USA) were transfected into the cells at a final oligonucleotide concentration of $30 \mathrm{pmol} / \mathrm{well}$ using Lipofectamine 2000 (Invitrogen) according to the manufacturer's instructions. The cells were incubated in a hypoxia workstation for $48 \mathrm{~h}$ prior to experiments.

Detection of miR-181b by TaqMan RT-PCR. Total RNA was extracted from cells using TRIzol (Invitrogen). The RT and $\mathrm{PCR}$ reactions were performed using the Hairpin-it ${ }^{\mathrm{TM}}$ miRNAs Real-Time PCR Quantitation kit (GenePharma, Shanghai, China). For reverse transcription (RT), the reaction was carried out as follows: $30 \mathrm{~min}$ at $16^{\circ} \mathrm{C}, 30 \mathrm{~min}$ at $42^{\circ} \mathrm{C}, 5 \mathrm{~min}$ at $85^{\circ} \mathrm{C}$, and then kept at $4^{\circ} \mathrm{C}$. The primer used for RT was GTCGTA TCCAGTGCGTGTCGTGGAGTCGGCAATTGCACTGGA TACGACACCCAC. The PCR amplification was conducted as follows: $95^{\circ} \mathrm{C}$ for 1 min followed by 40 cycles of $95^{\circ} \mathrm{C}$ for $15 \mathrm{sec}, 62^{\circ} \mathrm{C}$ for $15 \mathrm{sec}, 72^{\circ} \mathrm{C}$ for $30 \mathrm{sec}$, and a 30 -sec final extension at $37^{\circ} \mathrm{C}$. The relative amounts of miRNAs were normalized against the U6 RNA using the $2^{-\Delta \Delta \mathrm{Ct}}$ method, all experiments were performed in triplicate for each sample. The primers used for PCR amplification were: miR-181b forward, GGGAACATTCATTGCTG and reverse, CAGTGCGTGTC GTGGAGT; U6 forward, GCTTCGGCAGCACATATACTA AAAT and reverse, CGCTTCACGAATTTGCGTGTCAT.

Tube formation assay. Matrigel-coated (BD Pharmingen, San Jose, CA, USA) 24-well plates were incubated at $37^{\circ} \mathrm{C}$ for $2 \mathrm{~h}$ prior to the experiment. HUVECs were seeded onto the plates $\left(4 \times 10^{4}\right.$ cells/well) and cultured at $37^{\circ} \mathrm{C}$ for $6 \mathrm{~h}$ with i) M-199 medium in normal conditions, ii) M-199 medium in hypoxic conditions and iii) culture medium of pre-transfected retinoblastoma cells in hypoxic conditions. The number of the capillary-like structures was scanned and quantified under a light microscope (Zeiss, Aoboer Cohen, Germany) in five lower-power fields (magnification, x100).

Cell cytotoxicity assay. Vincristine (VCR), etoposide VP-16 (VP-16) and carboplatin were purchased from the Pharmaceutical Corporation of Qilu, China. HXO-RB44 cells were seeded into 96 -well plates $\left(6 \times 10^{5}\right.$ cells/well) and treated with VCR $(0.1,1,5$, and $10 \mu \mathrm{g} / \mathrm{ml}), \mathrm{VP}-16(2,20,100$, and $200 \mu \mathrm{g} / \mathrm{ml})$ and carboplatin $(2,20,100$, and $200 \mu \mathrm{g} / \mathrm{ml})$ at different concentrations, respectively. Wells with medium only were set as blank and wells with cells but no drugs as control. After being cultured under normal and hypoxic conditions for $72 \mathrm{~h}$, cell viability was determined by a CCK-8 Kit (Dojindo Laboratories, Kumamoto, Japan) according to the manufacturer's instructions. The 50\% inhibitory concentration $\left(\mathrm{IC}_{50}\right)$ for each drug was calculated according to a dose-response curve by non-linear regression analysis. Pre-transfected HXO-RB44 cells (miR-181b precursor, and inhibitor and negative control) were treated with drugs as mentioned above and the $\mathrm{IC}_{50}$ value was calculated. The experiments were performed three times and three parallel samples were measured each time. 
Bioinformatics analysis of target genes of miR-181b. Target genes of miR-181b were predicted by retrieving the miRBase (http://microrna.sanger.ac.uk/), TargetScan (http://www. targetscan.org) and Pictar (http://pictar.mdcberlin.de) databases. Target prediction was performed by applying the three algorithms and two experimentally validated databases: TarBase and miRecords (http://mirsystem.cgm.ntu.edu.tw/) provided by the miRSystem. Targets receiving more than three positive votes were selected as miR-181b targets for subsequent analysis to reduce the quantity of false-positive results.

Reverse transcription and PCR amplification. Extraction and assessment of RNA were performed as described above. RNA was reverse transcribed with reverse transcriptase to synthesize the cDNA using a random primer. Two micrograms of total RNA in a $25-\mu 1$ reaction was carried out at $42^{\circ} \mathrm{C}$ for $60 \mathrm{~min}$, then the reaction mixture was incubated at $95^{\circ} \mathrm{C}$ to inactivate the reverse transcriptase and denature the template. The PCR reaction was conducted in a final reaction volume of $25 \mu \mathrm{l}$ containing $2 \mu \mathrm{l}$ of cDNA, $1 \mu \mathrm{l}$ of gene-specific primers $(10 \mu \mathrm{M}), 0.2 \mu \mathrm{l}$ of dNTPs $(25 \mathrm{mM}), 1 \mu \mathrm{l}$ Taq DNA polymerase $(1 \mathrm{U} / \mu \mathrm{l})$ and $2.5 \mu \mathrm{l}$ of $10 \mathrm{X}$ buffer. The cycling conditions for the PCR reaction were: $95^{\circ} \mathrm{C}$ for $10 \mathrm{~min}$, followed by 35 cycles of $95^{\circ} \mathrm{C}$ for $20 \mathrm{sec}, 60^{\circ} \mathrm{C}$ for $20 \mathrm{sec}, 72^{\circ} \mathrm{C}$ for $30 \mathrm{sec}$, then followed by $72^{\circ} \mathrm{C}$ for $7 \mathrm{~min}$ and then kept at $4^{\circ} \mathrm{C}$. The amplified products were visualized using $2 \%$ agarose gel and ethidium bromide under UV transillumination. Expression was considered positive if the expected band of gene was observed. The gene-specific primers used for PCR were: visinin-like 1 (VSNL1) forward, ATGGGGAAACAGAATAGCAA and reverse, TCATTTCTGAATGTCACACTG; pleiomorphic adenoma gene 1 (PLAGl) forward, CAAGATTCTCAAGCAT CGTCA and reverse, TCCAAGGCTCCCCACTG; glutamate receptor 1 (GRIAl) forward, AAATCTACAGCAATGCTG GCGA and reverse, CTTCGATGACTTCTCTGTC; proteaseactivated receptors $4(P A R-4)$ forward, GGGACCTCGGAACT CAAC and reverse, TGTATCTGCCTGGGACTG; programmed cell death-10 (PDCD10) forward, CCTAAACGAA AAGGCACGAG and reverse, GCCCTGCGGTTCTGGTA; T-cell leukemia/lymphoma 1 (TCL1) forward, ATCATCG AGCTCCAGGCTGGAGCTGGTTTCCATG and reverse, ATCATCAGATCTCGTCCAAATACACGAACTTCTCCC; E2F transcription factor 5 (E2F5) forward, ATCCAGCATG GCAACTCAA and reverse, TCATCTGCCGGGGTAGGAG; GATA binding protein 6 (GATA6) forward, CTCCAACTTCC ACCTCTTCTAAC and reverse, GCCCATCTTGACCCGAAT.

Western blotting. The cells were incubated with buffer containing protease inhibitor cocktail $(0.01 \mathrm{mg} / \mathrm{ml}$ of aprotinin, pepstatin A and leupeptin) and PMSF (Sigma-Aldrich, St. Louis, MO, USA) at $4^{\circ} \mathrm{C}$ for $5 \mathrm{~min}$. The cells were lysed by sonicator (Episonic, Santa Ana, CA, USA) with $25 \%$ power for $1 \mathrm{~min}$, then centrifuged at $4^{\circ} \mathrm{C}(50,000 \mathrm{x}$ g for $20 \mathrm{~min})$ and the supernatant was transferred to a new sterile $1.5 \mathrm{ml} \mathrm{EP}$ tube. Protein concentrations were measured using the BCA Protein Assay kit (Bio-Rad, Hercules, CA, USA). The western blot analysis was subsequently performed. Briefly, $50 \mu \mathrm{g}$ of total protein was separated by SDS-PAGE on $10 \%$ gel and transferred onto PVDF membranes (Millipore, Billerica, MA, USA) at $200 \mathrm{~mA}$ for $1.5 \mathrm{~h}$. The membranes were incubated with primary antibodies (1:50 in 1\% BSA/TBST) overnight at $4^{\circ} \mathrm{C}$. The primary antibodies (mouse monoclonal) against PDCD10, GATA6, PLAG1 and E2F5 were all purchased from Bioworld (St. Louis, MN, USA). The membranes were incubated with secondary antibodies [1:5,000 in 1\% BSA/TBST, goat anti-mouse IRDye $800 \mathrm{CW}$, LI-COR Biosciences (Lincoln, NE, USA)] for $1 \mathrm{~h}$ at room temperature. The immunoreactivity of proteins was detected using an ECL reagent (Millipore). The mean density of each band was quantified using Image J software with tubulin (Sigma-Aldrich; 1:1,000 in $1 \%$ BSA/TBST), used as an internal control.

Statistical analysis. Data were presented as means \pm SD if not specified ortherwise. Statistical analysis was performed using SPSS 15.0 (SPSS Inc., Chicago, IL, USA). The difference between groups was analyzed using the unpaired Student's t-test (only two groups) or one-way analysis of variance (three or more groups) with significance accepted as $\mathrm{P}<0.05$.

\section{Results}

Upregulation of $\mathrm{miR}-181 \mathrm{~b}$ in retinoblastoma cells under hypoxia is HIF-1 $\alpha$ independent. Our previous findings (11) confirmed that hypoxia upregulated the expression of miR-181b in retinoblastoma cells. Since HIF-1 $\alpha$ is the master regulator of transcription factors under hypoxic conditions, we aimed to determine whether the expression of miR-181b is regulated by HIF-1 $\alpha$. We detected the expression of HIF-1 $\alpha$ in retinoblastoma cells under normal and hypoxic conditions, respectively, and found a 2.4-fold increased expression of HIF-1 $\alpha$ under hypoxia as compared to normal conditions (Fig. 1A). To better understand the connection between HIF-1 $\alpha$ and miR-181b, we reduced the level of HIF-1 $\alpha$ using siRNA technology. In order to silence the target gene more effectively, we designed three pairs of different sequences of siRNA (HIF-1 $\alpha-816$ targeted 816-836 sites, HIF-1 $\alpha-1171$ targeted 1171-1191 sites and HIF-1 $\alpha-1504$ targeted 1504-1524 sites). Quantitative PCR results showed HIF-1 $\alpha-1504$ reduced the level of HIF- $1 \alpha>50 \%$ (Fig. 1B). However, the expression of HIF-1 $\alpha$ was largely blocked by siHIF-1 $\alpha-1504$, and no significant change of the expression of miR-181b (Fig. 1C) was identified, indicating that the increased expression of miR-181b under hypoxia was not regulated by HIF- $1 \alpha$.

Hypoxia enhances the capacity of tube formation of HUVECs. To examine the effect of hypoxia on the ability of tube formation of HUVECs, HUVECs were exposed to normoxia or hypoxia for $6 \mathrm{~h}$, and the capillary-like structures were calculated. The results showed HUVECs formed more capillary-like structures under hypoxia than under normoxia (Fig. 2).

miR-181b significantly promotes capillary tube formation of HUVECs under hypoxia. To examine the biological mechanism of miR-181b in tumor-hypoxic responses, we further detected the effect of miR-181b on the ability of capillary tube formation of HUVECs in vitro. Retinoblastoma cells were transfected with miR-181b precursor and inhibitor to upregulate or downregulate their miR-181b levels. Their culture medium was added 

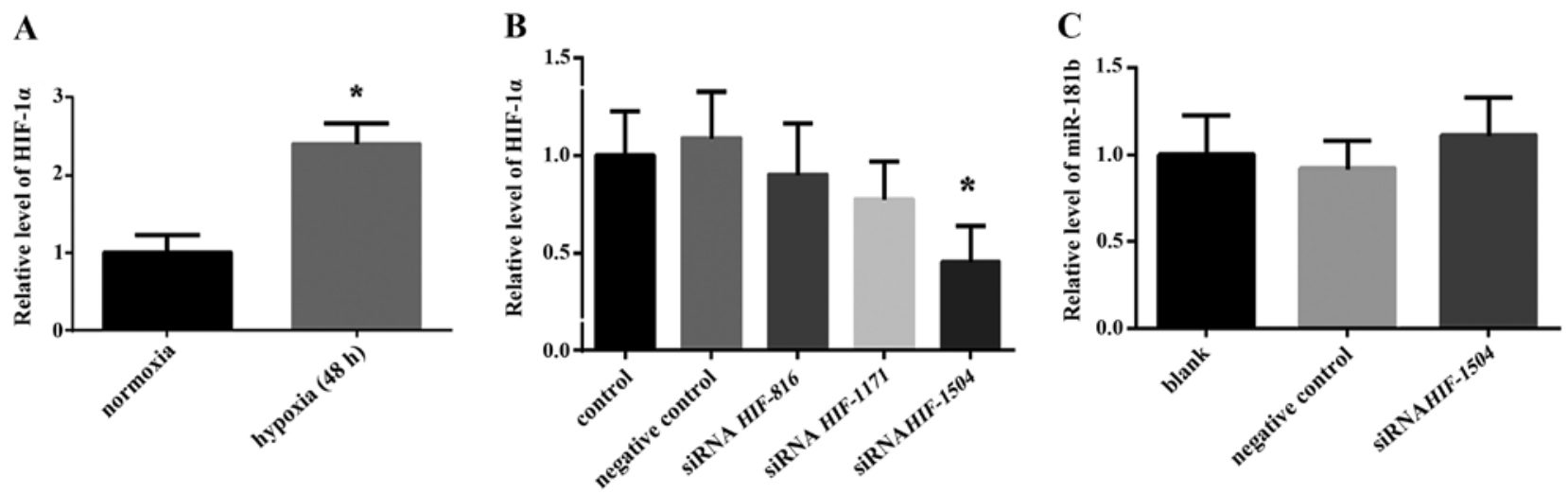

Figure 1. Hypoxia-induced miR-181b overexpression in retinoblastoma cells (HXO-RB44) was not regulated by hypoxia-inducible factor-1 $\alpha$ (HIF-1 $\alpha$ ). (A) When exposed to hypoxia for $48 \mathrm{~h}$, the expression of HIF-1 $\alpha$ in HXO-RB44 cells was upregulated compared to normal conditions. (B) HXO-RB44 cells were transfected with small-interfering RNAs (siRNAs) against HIF-1 $\alpha$ or scrambled sequence as control under hypoxic conditions, while the sequence siHIF-1 $\alpha-1504$ decreased the expression of HIF-1 $\alpha$ effectively. (C) The level of miR-181b was not suppressed by siHIF-1 $\alpha-1504$ simultaneously. The data are presented as means $\pm \mathrm{SD}\left({ }^{*} \mathrm{P}<0.01\right)$.

A
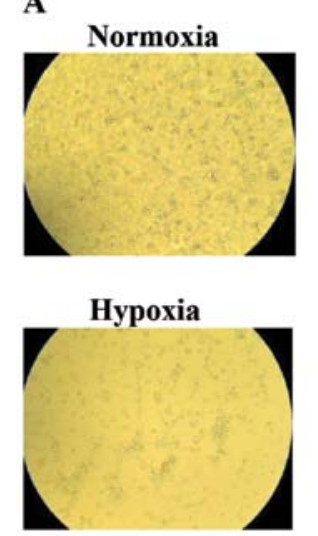

B

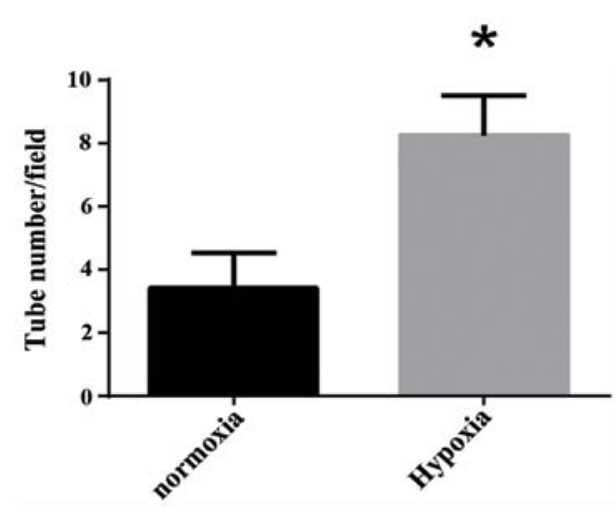

Figure 2. Human umbilical vein endothelial cells (HUVECs) formed more capillary-like structures when exposed to hypoxic conditions. After being cultured under low-oxygen conditions for $6 \mathrm{~h}$, the ability of capillary tube formation of HUVECs was significantly increased compared to under normoxia ("P<0.01).
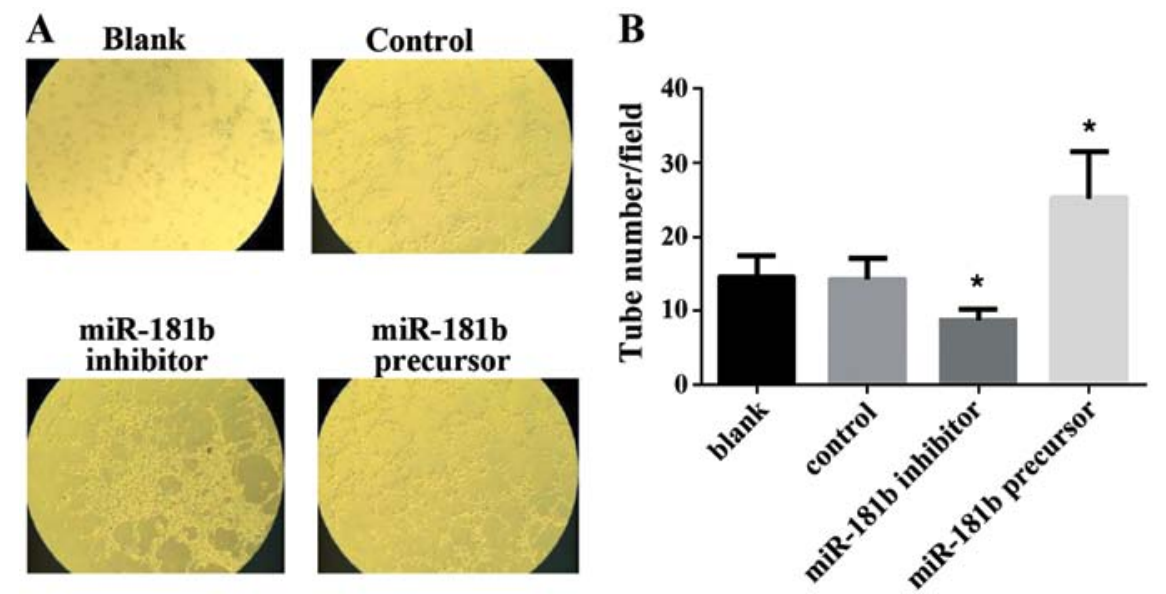

Figure 3. miR-181b enhanced capillary tube formation of human umbilical vein endothelial cells (HUVECs) in vitro. HUVECs were cultured with culture medium of retinoblastoma cells (pre-transfected with miR-181b precursor, and inhibitor and the negative control, respectively) or ordinary M-199 medium as blank for $6 \mathrm{~h}$ under hypoxic conditions. Medium of miR-181b precursor increased the ability of tube formation of HUVECs while the medium of miR-181b inhibitor reduced the ability of tube formation compared with the control (" $\mathrm{P}<0.01)$.

to HUVECs. The culture medium of miR-181b precursortransfected retinoblastoma cells significantly increased the capillary tube formation of HUVECs. By contrast, the medium of miR-181b inhibitor led to the suppression of tube formation of HUVECs. The results suggested that miR-181b enhanced the angiogenesis of HUVECs in vitro (Fig. 3). 

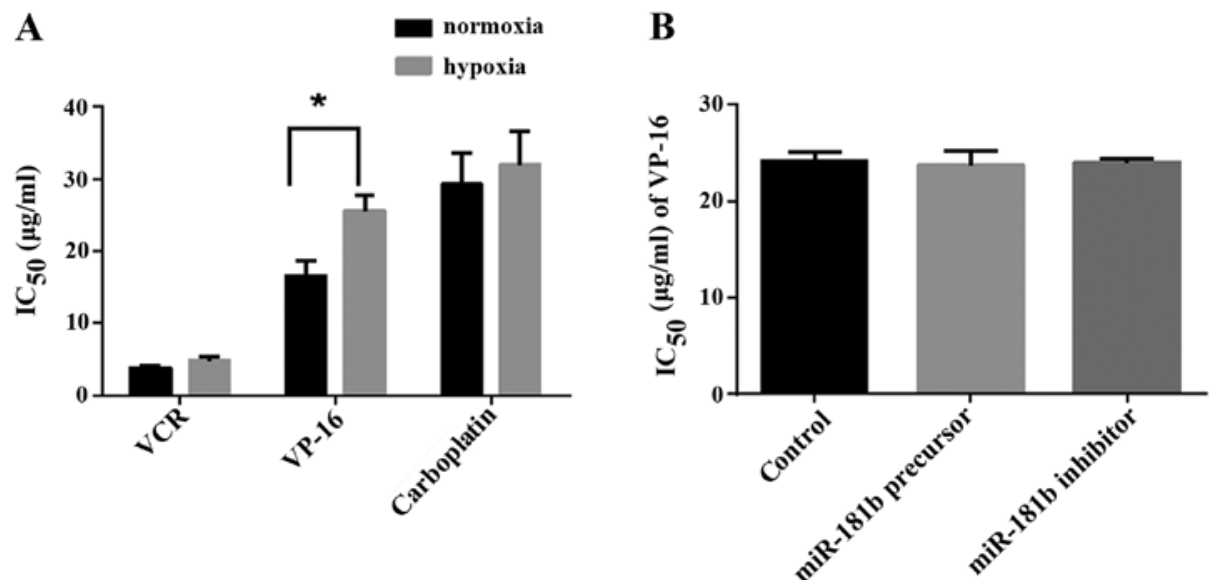

Figure 4. Induced chemoresistance to VP-16 by hypoxia is independent of miR-181b in retinoblastoma cells. $\mathrm{IC}_{50}$ of drugs was assessed to determine the chemoresistance of drugs. (A) After being cultured under hypoxia for $72 \mathrm{~h}$, only $\mathrm{IC}_{50}$ of VP-16 was increased significantly ("P $<0.01$ ). (B) Pre-transfected (miR-181b precursor,and inhibitor and control) cells were treated with VP-16 under hypoxia for $72 \mathrm{~h}$. No significant change of $\mathrm{IC}_{50}$ compared to the control was identified, indicating hypoxia-induced chemoresistance of VP-16 is independent of miR-181b $(\mathrm{P}>0.05)$.

\begin{tabular}{|c|c|c|}
\hline Gene & Putative binding sites & \\
\hline & $\begin{array}{l}5^{\prime} . . . \text { UUAUUAAGCUAAUAAUGAAUGUU.... } \\
\text { IIIIIIII }\end{array}$ & $3501-3507$ \\
\hline leiomorphic & 3' UGGGUGGCUGUCGUUACUUACAA & miR-181b \\
\hline $\begin{array}{l}\text { adenomagene } 1 \\
\text { (PLAG1) }\end{array}$ & $\begin{array}{r}5^{\prime} \ldots \text {...ACAGAUGAACCAGAAUGAAUGUU... } \\
\text { IIIIIII }\end{array}$ & 4389-4395 \\
\hline & 3' UGGGUGGCUGUCGUUACUUACAA & $\operatorname{miR}-181 \mathrm{~b}$ \\
\hline GATA binding & $5^{\prime} \ldots$...AGCAUUUUUUU AUAAUGAAUGUA... & $720-726$ \\
\hline protein 6(GATA6) & 3' UGGGUGGCUGUCGUUACUUACAA & $\mathrm{miR}-181 \mathrm{~b}$ \\
\hline $\begin{array}{l}\text { E2F transcription } \\
\text { factor } 5 \text { (E2F5) }\end{array}$ & $\begin{array}{l}5^{\prime} . . . \text { AAAUAUUUUAAAUAAUGAAUGUA... } \\
\text { IIIIIIIII }\end{array}$ & $83-89$ \\
\hline & 3' UGGGUGGCUGUCGUUACUUACAA & miR-181b \\
\hline & $\begin{array}{l}5^{\prime} \text {...UUUUAAACUACUGAUUGAAUGUU... } \\
\text { IIIII }\end{array}$ & $44-50$ \\
\hline receptors 4 (PAR4) & 3' UGGGUGGCUGUCGUUACUUACAA & $\operatorname{miR}-181 b$ \\
\hline $\begin{array}{l}\text { programmed cell } \\
\text { death-10 }\end{array}$ & ...CAU-GUUAGUUGCCAGCUACC & $348-370$ \\
\hline (PDCD10) & GT ATTTAA C AA TAT T TGGTGG & miR-181b \\
\hline & $\begin{array}{l}5^{\prime} \quad \text {..CCAGGCCGGCGAGCCCUGUGGAUG } \\
||:|||:| \quad|||:||:|||\end{array}$ & \\
\hline lymphoma & GG GUGGCUG UCGUUACUUAC & miR-181b \\
\hline ate receptor 1 & $\begin{array}{c}5 \text { '...GCCUACAGCGACAAU-.-UGAAUGUU... } \\
|||||||||| \mid\end{array}$ & $232-238$ \\
\hline (GRI & 3' GGGUGGCUGUCGUUACUUACAA & miR-181b \\
\hline Visinin-lik & $\begin{array}{l}5^{\prime} \quad \text {...GGGUGGCUGU-CGUUACUUACAA } \\
\quad|\|:|||||:|||||| \mid\end{array}$ & $313-336$ \\
\hline & $3^{\prime} \quad$ C C C G GC GCCATCTCCGTGAATGTT & $\operatorname{miR}-181 b$ \\
\hline
\end{tabular}

Figure 5. Bioinformatics analysis predicted target genes of miR-181b. There were eight predicted target genes that contained putative binding sites for miR-181b at the 3'-untranslated region (3'-UTR).

Induced chemoresistance to VP-16 by hypoxia is independent of miR-181b in retinoblastoma cells. To elucidate the possible role of miR-181b as a hypoxic responses regulator, we examined the effect of miR-181b on chemoresistance in retinoblastoma cells. VCR, VP-16 and carboplatin are the most widely used chemotherapeutic agents in retinoblastoma. The regimen containing these three drugs has become the first-line therapy for retinoblastoma in recent years. We used $\mathrm{IC}_{50}$ which describes the concentration of the drugs that lead to inhibition of cell growth in $50 \%$ of the treated cells to represent the chemoresistance. If a drug has a higher $\mathrm{IC}_{50}$, stronger cell resistance to drugs should be considered. When exposed to hypoxic conditions for $72 \mathrm{~h}$, the $\mathrm{IC}_{50}$ values of three drugs were higher than those of the normal conditions, with only the difference of VP-16 (25.66 vs. $16.57 \mu \mathrm{g} / \mathrm{ml})$ being statistically significant (Fig. 4A). It meant that hypoxia was one of the incentives of acquired resistance of VP-16. We further characterized the role of miR-181b in regulating hypoxia-induced chemoresistance of VP-16 by modulating its levels in retinoblastoma cells. But transient transfection of miR-181b precursor and inhibitor did not show any effect on the $\mathrm{IC}_{50}$ of VP-16 compared to control (23.76, 24.03 and $24.17 \mu \mathrm{g} / \mathrm{ml}$, respectively, Fig. 4B). The date indicated hypoxia-induced chemoresistance of VP-16 in retinoblastoma cells was miR-181b-independent.

Prediction of target genes of miR181b. The conservation of the miRNA binding sites in the 3'-UTR of the orthologous genes is a significant feature in predicting miRNA targets. It is conceivable that the use of multiple prediction tools lead to a higher confidence in predicting miRNA target gene pairs. We adopted a consensus target prediction approach of using multiple miRNA target prediction databases: miRBase, TargetScan and PicTar to identify target genes of miR-181b. Eight genes contained predicted binding site for miR-181b at 3'-UTR (Fig. 5). Further investigation was performed to exclude the false-positive. We detected the mRNA level of these genes and found GATA6, PDCD10, PLAG1 and E2F5 were steadily expressed in retinoblastoma cells (Fig. 6). The four genes were selected as candidates of miR-181b.

miR-181b inhibits PDCD10 and GATA6 production in retinoblastoma cells. We examined the regulation of miR-181b on the expression of the four genes mentioned above by western blotting. The results showed that pretreatment with miR-181b precursor decreased PDCD10 and GATA6 expression while pretreated miR-181b inhibitor increased PDCD10 and GATA6 expression (Fig. 7). These results suggested that miR-181b acted as a negative regulator of PDCD10 and GATA6 under hypoxia in retinoblastoma cells. 

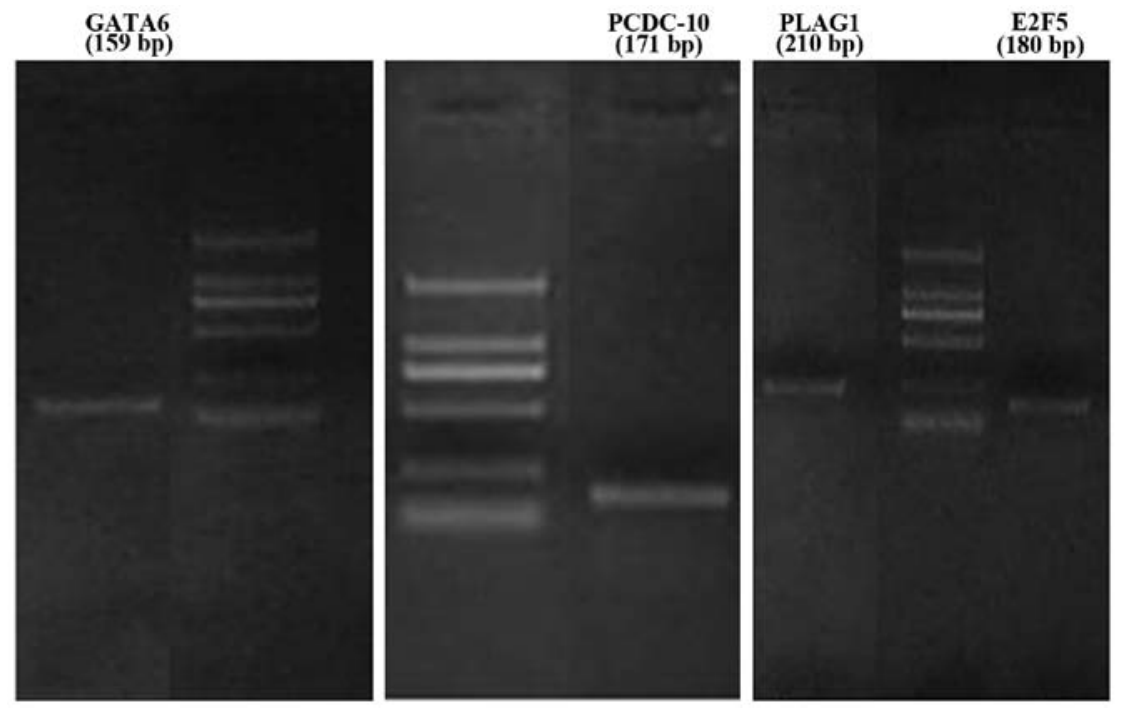

Figure 6. RT-PCR detected the expression of potential target genes in retinoblastoma cells. The GATA6, PDCD10, PLAG1 and E2F5 genes were steadily expressed in retinoblastoma cells. GATA6, GATA binding protein 6; PDCD10, programmed cell death-10; PLAG1, pleiomorphic adenoma gene 1; E2F5, E2F transcription factor 5 .

A
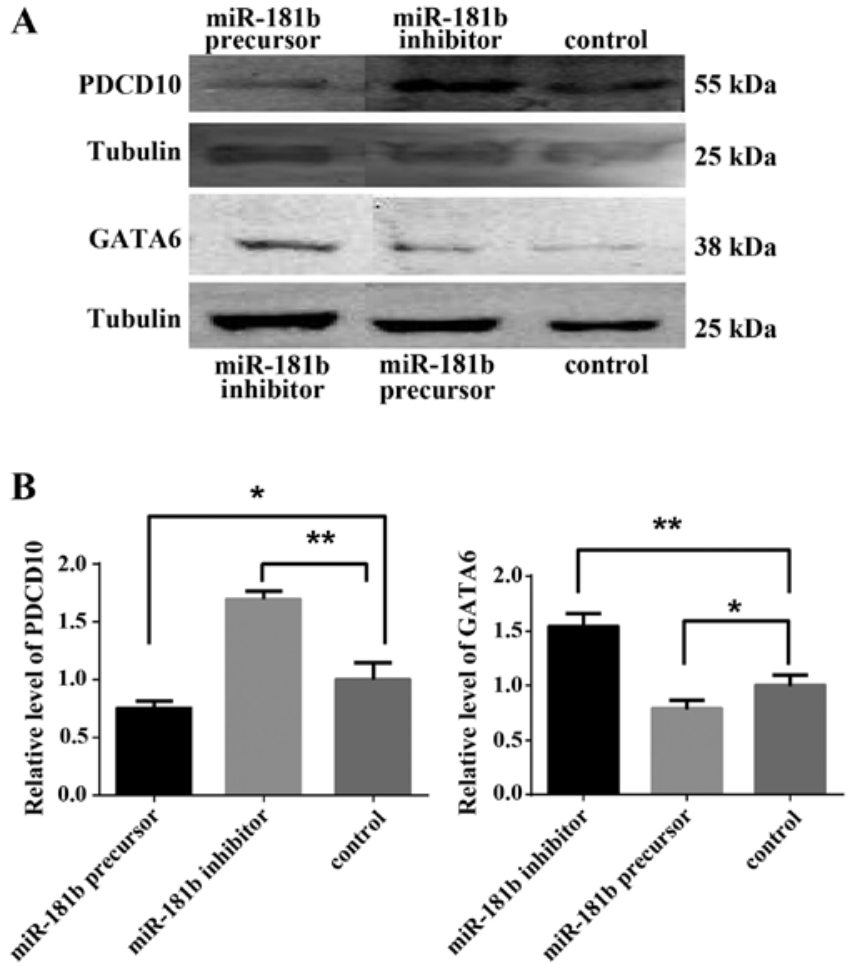

Figure 7. Regulation of miR-181b on the expression of PDCD10 and GATA6. The levels of PDCD10 and GATA6 expression were obviously inhibited by transfection with miR-181b precursor to upregulate miR-181b level in cells, while knockdown of miR-181b with miR-181b inhibitor, showed a significantly increased expression of PDCD10 and GATA6 $\left({ }^{*} \mathrm{P}<0.05,{ }^{* *} \mathrm{P}<0.01\right)$. GATA6, GATA binding protein 6; PDCD10, programmed cell death-10.

\section{Discussion}

Hypoxia is an important pathological process of solid tumors, and hypoxic regions are present in retinoblastoma (12). The findings of our previous study showed that miR-181b was upregulated by hypoxia in retinoblastoma cells, although the molecular mechanisms of responses to hypoxia remained unknown. HIF-l is the most studied gene that plays a central role in cancer hypoxic responses (13). HIF-1 is composed of HIF $1 \alpha$ and HIF1 $\beta$ subunits. HIF- $1 \alpha$ is considered as the most important regulator under hypoxic conditions in various solid tumors and a high expression of HIF-1 $\alpha$ was confirmed in the progression of retinoblastoma (14-16). Many miRNAs, such as miR-21, -210, -103 and -195 were reported to be induced and upregulated by HIF-1 $\alpha$ in cancer cells under hypoxic conditions $(17,18)$. Thus, whether miR-181b is also a controlled candidate of HIF-1 $\alpha$ remains to be determined. Results of this study showed that the expression of HIF-1 $\alpha$ in retinoblastoma cells was elevated substantially following exposure to hypoxia for $48 \mathrm{~h}$. When using HIF-1 $\alpha$ siRNA to reduce the level of HIF-1 $\alpha$, the repression of miR-181b was not observed synchronously. These results suggested the expression of miR-181b under hypoxia was not regulated by HIF-1 $\alpha$. A possible explanation for this finding is that HIF- $1 \alpha$ may be crucial under hypoxic conditions but it is not the single regulatory factor. Mounting evidence has indicated HIF alone is insufficient to implement the full program of adaptive changes of cancer under hypoxic stress. Recently, transcription factors responding to hypoxia, such as p53 and NF- $\kappa \mathrm{B}$, have been shown to affect the expression of selected miRNAs (19-21). Instead, mTOR, endoplasmic reticulum (ER) stress were also reported to be involved in hypoxic responses via HIF-independent pathways $(22,23)$. It seems that miRNAs interface with both HIF-driven and -independent pathways to form an interconnected regulatory network under hypoxic stress. We have demonstrated that miR-181b transcriptional upregulation in hypoxia in retinoblastoma is HIF- $1 \alpha$-independent. However, additional studies are needed to identify the network between miR-181b and hypoxia in retinoblastoma.

miR181-b is a type of miRNA endogenously expressed in cells of the inner and middle retina. Dysregulated expression of miR-181b has been demonstrated in different tumors $(24,25)$. Retinoblastoma is a malignancy originating from the retina. However, to the best of our knowledge, there are no reports available concerning the possible roles of miR-181b in the devel- 
opment of retinoblastoma. We have identified miR-181b as an HRM of retinoblastoma in a previous study (11). Since chemoresistance and angiogenesis were main responses to hypoxia in many tumors including retinoblastoma, we examined the functions of miR-181b in hypoxic responses of retinoblastoma. Firstly, we determined the influence of hypoxia on the ability of tube formation of HUVECs and found HUVECs formed more capillary tubes under hypoxic as compared to normal conditions. Subsequently, through up- and downregulation of miR-181b expression in retinoblastoma cells, we demonstrated that miR-181b enhanced the ability of capillary tube formation of HUVECs in vitro. Additionally, we identified that retinoblastoma cells showed a stronger resistance to VP-16 in hypoxic conditions, although the same chemoresistance was not observed in VCR and carboplatin (these three were the most popularly used chemotherapy drugs in retinoblastoma). Further investigation suggested the chemoresistance induced by hypoxia was miR-181b-independent. These results, however, were not consistent with those of previous studies and there is controversy regarding the roles of miR-181b in human malignancies. For instance, Sun et al reported overexpression of miR-181b increased the sensitivity of glioma cells to teniposide, while Takiuchi et al found miR-181b led to the resistance of pancreatic cancer cells to gemcitabine by activating $\mathrm{NF}-\kappa \mathrm{B}(26,27)$. These discordant findings suggested that miR$181 \mathrm{~b}$ may play organ-specific roles in part due to the different cell contexts of tumors and pharmacological characteristics. To the best of our knowledge, the present study provides the first evidence that hypoxia-induced miR-181b may play a critical role in angiogenesis and metastasis in retinoblastoma.

To gain insight into the molecular mechanism involved in the function of miR-181b, we predicted eight target genes of miR-181b using bioinformatics analysis. This prediction was further confirmed by evaluating the effects of up- and downregulation of miR-181b on specific target gene expression in retinoblastoma cells. We also determined PDCD10 and GATA6 as downstream genes of miR-181b. PDCD10 (also known as cerebral cavernous malformation 3, CCM3) was expressed in endothelial cells and was essential for vascular development (28). Previous results showed silencing CCM3 or loss of CCM3 (decreased expression of CCM3) stimulated sprouting and tube branching or activated endothelial angiogenesis (29-31). These data indicated the roles of PDCD10 as an anti-angiogenic transcription factor in vascular development/maturation. GATA6 is a transcription factor belonging to the GATA family which controls the development and differentiation of a wide spectrum of cell lineages especially in HUVECs. Considerable evidence suggests the importance of GATA6 in the regulation of vascular endothelial cells, which enables angiogenic function and endothelial cell survival (32). GATA gene families may be involved in regulating homeostasis of the eye vasculature (33). Evidence also suggested GATA6 as a target for repression by miR-181s (34). In agreement with the abovementioned results, we found that upregulation of $\mathrm{miR}-181 \mathrm{~b}$ in retinoblastoma cells inhibited the expression of PDCD10 and GATA6, weakened the anti-angiogenic functions of PDCD10 and GATA6, and promoted the angiogenesis of retinoblastoma cells.

In conclusion, there were three important results in the present study: hypoxia-induced overexpression of miR-181b in retinoblastoma cells is HIF-1 $\alpha$ independent; miR-181b significantly increased the ability of capillary tube formation of HUVECs; and the enhanced effects of miR-181b on angiogenesis may be due to the decreased expression of PDCD10 and GATA6. Our results suggest that miR-181b acts as an oncogenic miRNA in retinoblastoma cells to promote metastasis under a hypoxic microenvironment. These results add to the mounting evidence that miR-181b is crucial in promoting cancer development and may assist in the development of new therapeutic regimens against hypoxic tumors.

\section{Acknowledgements}

This study was supported by the Scientific Research Program of the National Health and Family Planning Commission of China (no. 2014040), the National Nature Science Foundation of China (nos. 81372469 and 81372909), and the Science and Technology Commission of Shanghai (nos. 12ZR1417300 and 13JC1406202).

\section{References}

1. Kivelä T: The epidemiological challenge of the most frequent eye cancer: retinoblastoma, an issue of birth and death. $\mathrm{Br} \mathrm{J}$ Ophthalmol 93: 1129-1131, 2009.

2. Chintagumpala M, Chevez-Barrios P, Paysse EA, Plon SE and Hurwitz R: Retinoblastoma: review of current management. Oncologist 12: 1237-1246, 2007.

3. Chantada GL, Qaddoumi I, Canturk S, Khetan V, Ma Z, Kimani K, Yeniad B, Sultan I, Sitorus RS, Tacyildiz N, et al: Strategies to manage retinoblastoma in developing countries. Pediatr Blood Cancer 56: 341-348, 2011.

4. Canturk S, Qaddoumi I, Khetan V, Ma Z, Furmanchuk A, Antoneli CB, Sultan I, Kebudi R, Sharma T, Rodriguez-Galindo C, et al: Survival of retinoblastoma in less-developed countries impact of socioeconomic and health-related indicators. Br J Ophthalmol 94: 1432-1436, 2010.

5. Lee YJ, Lee JH, Moon JH and Park SY: Overcoming hypoxic resistance of tumor cells to TRAIL-induced apoptosis through melatonin. Int J Mol Sci 15: 11941-11956, 2014.

6. Harris AL: Hypoxia - a key regulatory factor in tumour growth. Nat Rev Cancer 2: 38-47, 2002.

7. Gruber M and Simon MC: Hypoxia-inducible factors, hypoxia, and tumor angiogenesis. Curr Opin Hematol 13: 169-174, 2006.

8. Greco S and Martelli F: MicroRNAs in hypoxia response. Antioxid Redox Signal 21: 1164-1166, 2014.

9. McCarthy N: Hypoxia: micro changes. Nat Rev Cancer 14: 382-383, 2014.

10. Qin Q, Furong W and Baosheng L: Multiple functions of hypoxiaregulated miR-210 in cancer. J Exp Clin Cancer Res 33: 50, 2014.

11. Xu X, Jia R, Zhou Y, Song X, Wang J, Qian G, Ge S and Fan X: Microarray-based analysis: Identification of hypoxia-regulated microRNAs in retinoblastoma cells. Int J Oncol 38: 1385-1393, 2011.

12. Boutrid H, Jockovich ME, Murray TG, Piña Y, Feuer WJ, Lampidis TJ and Cebulla CM: Targeting hypoxia, a novel treatment for advanced retinoblastoma. Invest Ophthalmol Vis Sci 49: 2799-2805, 2008.

13. Lan KL, Lan KH, Sheu ML, Chen MY, Shih YS, Hsu FC, Wang HM, Liu RS and Yen SH: Honokiol inhibits hypoxiainducible factor-1 pathway. Int J Radiat Biol 87: 579-590, 2011.

14. Tsai YP and Wu KJ: Hypoxia-regulated target genes implicated in tumor metastasis. J Biomed Sci 19: 102, 2012.

15. Voss MJ, Niggemann B, Zänker KS and Entschladen F: Tumour reactions to hypoxia. Curr Mol Med 10: 381-386, 2010.

16. Sudhakar J, Venkatesan N, Lakshmanan S, Khetan V, Krishnakumar S and Biswas J: Hypoxic tumor microenvironment in advanced retinoblastoma. Pediatr Blood Cancer 60: 1598-1601, 2013.

17. Bao B, Ali S, Ahmad A, Azmi AS, Li Y, Banerjee S, Kong D, Sethi S, Aboukameel A, Padhye SB, et al: Hypoxia-induced aggressiveness of pancreatic cancer cells is due to increased expression of VEGF, IL-6 and miR-21, which can be attenuated by CDF treatment. PLoS One 7: e50165, 2012. 
18. Kulshreshtha R, Ferracin M, Wojcik SE, Garzon R, Alder H, Agosto-Perez FJ, Davuluri R, Liu CG, Croce CM, Negrini M, et al: A microRNA signature of hypoxia. Mol Cell Biol 27: 1859-1867, 2007.

19. He L, He X, Lim LP, De Stanchina E, Xuan Z, Liang Y, Xue W, Zender L, Magnus J, Ridzon D, et al: A microRNA component of the p53 tumour suppressor network. Nature 447: 1130-1134, 2007.

20. Sermeus A and Michiels C: Reciprocal influence of the p53 and the hypoxic pathways. Cell Death Dis 2: e164, 2011.

21. Kluiver J, van den Berg A, De Jong D, Blokzijl T, Harms G, Bouwman E, Jacobs S, Poppema S and Kroesen BJ: Regulation of pri-microRNA BIC transcription and processing in Burkitt lymphoma. Oncogene 26: 3769-3776, 2007.

22. Koritzinsky M, Magagnin MG, van den Beucken T, Seigneuric R, Savelkouls K, Dostie J, Pyronnet S, Kaufman RJ, Weppler SA, Voncken JW, et al: Gene expression during acute and prolonged hypoxia is regulated by distinct mechanisms of translational control. EMBO J 25: 1114-1125, 2006.

23. Zhao L and Ackerman SL: Endoplasmic reticulum stress in health and disease. Curr Opin Cell Biol 18: 444-452, 2006.

24. Xi Y, Formentini A, Chien M, Weir DB, Russo JJ, Ju J, Kornmann $\mathrm{M}$ and $\mathrm{Ju} \mathrm{J}$ : Prognostic values of microRNAs in colorectal cancer. Biomark Insights 2: 113-121, 2006.

25. Nakajima G, Hayashi K, Xi Y, Kudo K, Uchida K, Takasaki K, Yamamoto $\mathrm{M}$ and Ju J: Non-coding MicroRNAs hsa-let-7g and hsa-miR-181b are associated with chemoresponse to S-1 in colon cancer. Cancer Genomics Proteomics 3: 317-324, 2006.

26. Sun YC, Wang J, Guo CC, Sai K, Wang J, Chen FR, Yang QY, Chen YS, Wang J, To TS, et al: miR-181b sensitizes glioma cells to teniposide by targeting MDM2. BMC Cancer 14: 611, 2014.
27. Takiuchi D, Eguchi H, Nagano H, Iwagami Y, Tomimaru Y, Wada H, Kawamoto K, Kobayashi S, Marubashi S, Tanemura M, et al: Involvement of microRNA-181b in the gemcitabine resistance of pancreatic cancer cells. Pancreatology 13: 517-523, 2013.

28. He Y, Zhang H, Yu L, Gunel M, Boggon TJ, Chen H and Min W: Stabilization of VEGFR2 signaling by cerebral cavernous malformation 3 is critical for vascular development. Sci Signal 3: ra26, 2010.

29. Zhu Y, Wu Q, Xu JF, Miller D, Sandalcioglu IE, Zhang JM and Sure U: Differential angiogenesis function of CCM2 and CCM3 in cerebral cavernous malformations. Neurosurg Focus 29: E1, 2010.

30. Schleider E, Stahl S, Wüstehube J, Walter U, Fischer A and Felbor U: Evidence for anti-angiogenic and pro-survival functions of the cerebral cavernous malformation protein 3 . Neurogenetics 12 : 83-86, 2011.

31. You C, Sandalcioglu IE, Dammann P, Felbor U, Sure U and Zhu Y: Loss of CCM3 impairs DLL4-Notch signalling: implication in endothelial angiogenesis and in inherited cerebral cavernous malformations. J Cell Mol Med 17: 407-418, 2013.

32. Perlman H, Suzuki E, Simonson M, Smith RC and Walsh K: GATA-6 induces p21(Cip1) expression and G1 cell cycle arrest. J Biol Chem 273: 13713-13718, 1998.

33. Crawford SE, Qi C, Misra P, Stellmach V, Rao MS, Engel JD, Zhu Y and Reddy JK: Defects of the heart, eye, and megakaryocytes in peroxisome proliferator activator receptor-binding protein (PBP) null embryos implicate GATA family of transcription factors. J Biol Chem 277: 3585-3592, 2002.

34. Ji J, Yamashita T, Budhu A, Forgues M, Jia HL, Li C, Deng C, Wauthier E, Reid LM, Ye QH, et al: Identification of microRNA-181 by genome-wide screening as a critical player in EpCAM-positive hepatic cancer stem cells. Hepatology 50: 472-480, 2009. 